\title{
Proposal for a New Pathologic Prognostic Index After Neoadjuvant Chemotherapy in Pancreatic Ductal Adenocarcinoma (PINC)
}

\author{
M. Redegalli, $\mathbf{P h D}^{\mathbf{1}}$, M. Schiavo Lena, $\mathbf{M D}^{\mathbf{1}}$, M. G. Cangi, $\mathbf{P h D}^{\mathbf{1}}$, C. E. Smart, MD, $\mathbf{P h D}^{\mathbf{1}}$, \\ M. Mori, $\mathrm{DMP}^{3}$, C. Fiorino, $\mathrm{PhD}^{3}$, P. G. Arcidiacono, $\mathrm{MD}^{4}$, G. Balzano, $\mathrm{MD}^{5}$, M. Falconi, $\mathrm{MD}^{5}$, \\ M. Reni, $\mathrm{MD}^{2}$ (D), and C. Doglioni, $\mathrm{MD}^{1}$
}

${ }^{1}$ Pathology Unit, IRCCS San Raffaele Scientific Institute, Vita-Salute San Raffaele University, Milan, Italy; ${ }^{2}$ Department of Medical Oncology, IRCCS San Raffaele Scientific Institute, Pancreas Translational and Clinical Research Centre, Milan, Italy; ${ }^{3}$ Medical Physics, San Raffaele Scientific Institute, Milan, Italy; ${ }^{4}$ Pancreato-Biliary Endoscopy and Endosonography Division, Pancreas Translational and Clinical Research Centre, San Raffaele Scientific Institute, Vita Salute San Raffaele University, Milan, Italy; ${ }^{5}$ Pancreatic Surgery Unit, Pancreas Translational and Clinical Research Centre, IRCCS San Raffaele Scientific Institute, Vita-Salute San Raffaele University, Milan, Italy

\begin{abstract}
Background. Limited information is available on the relevant prognostic variables after surgery for patients with pancreatic ductal adenocarcinoma (PDAC) subjected to neoadjuvant chemotherapy (NACT). NACT is known to induce a spectrum of histological changes in PDAC. Different grading regression systems are currently available; unfortunately, they lack precision and accuracy. We aimed to identify a new quantitative prognostic index based on tumor morphology.

Patients and Methods. The study population was composed of 69 patients with resectable or borderline resectable PDAC treated with preoperative NACT (neoadjuvant group) and 36 patients submitted to upfront surgery (upfront-surgery group). A comprehensive histological assessment on hematoxylin and eosin (H\&E)
\end{abstract}

M. Redegalli and M. Schiavo Lena have contributed equally to this manuscript and share first authorship.

M. Reni and C. Doglioni are shared the senior authorship.

(C) The Author(s) 2022

First Received: 13 September 2021

Accepted: 16 January 2022;

Published Online: 1 March 2022

M. Reni, MD

e-mail: reni.michele@hsr.it stained sections evaluated 20 morphological parameters. The association between patient survival and morphological variables was evaluated to generate a prognostic index. Results. The distribution of morphological parameters evaluated was significantly different between upfront-surgery and neoadjuvant groups, demonstrating the effect of NACT on tumor morphology. On multivariate analysis for patients that received NACT, the predictors of shorter overall survival (OS) and disease-free survival (DFS) were perineural invasion and lymph node ratio. Conversely, high stroma to neoplasia ratio predicted longer OS and DFS. These variables were combined to generate a semiquantitative prognostic index based on both OS and DFS, which significantly distinguished patients with poor outcomes from those with a good outcome. Bootstrap analysis confirmed the reproducibility of the model.

Conclusions. The pathologic prognostic index proposed is mostly quantitative in nature, easy to use, and may represent a reliable tumor regression grading system to predict patient outcomes after NACT followed by surgery for PDAC.

Pancreatic ductal adenocarcinoma (PDAC) is one of the most lethal malignancies. ${ }^{1}$ Over $50 \%$ of patients are metastatic at diagnosis, while only $10-20 \%$ of patients are diagnosed with resectable disease. Even though surgery is still the mainstay of therapy, early systemic relapses occur in up to $80 \%$ of cases after surgical management intended 
to be curative. ${ }^{2}$ The rapid appearance of recurrence strongly suggests the presence of subclinical diffusion in early phase disease. Furthermore, due to postoperative complications, a significant percentage of patients are unable to start any kind of chemotherapy that implies significant toxic effects. In the APACT study, ${ }^{3}$ comparing the association of gemcitabine and nab-paclitaxel to gemcitabine alone as adjuvant therapy in resected PDAC patients, only $866(71 \%)$ patients were randomized out of 1226 screened patients. The screening failure was mainly related to evidence of either potential residual or metastatic disease. Moreover, only 69\% of randomized patients completed the planned six cycles of chemotherapy (nabpaclitaxel/gemcitabine, $66 \%$; gemcitabine, $71 \%$ ). ${ }^{3}$

Accordingly, a preoperative therapeutic strategy is worthy of investigation, and several ongoing trials are exploring the role of NACT in early stage PDAC. Neoadjuvant chemotherapy (NACT) has been tested in a few randomized studies, which suggest benefits compared with up-front resection followed by adjuvant therapy., ${ }^{4,5}$ NACT is now considered an acceptable option for treatment of resectable and borderline resectable PDAC by the National Comprehensive Cancer Network (NCCN) guidelines. ${ }^{6}$ However, no information is available on the optimal therapeutic management after surgery for patients who have undergone NACT. This information gap is also due to a lack of prognostic stratification factors in these patients.

NACT is known to induce a spectrum of histological changes in PDAC. ${ }^{7,8}$ Since the 1980 s, several groups have proposed histopathological systems for the grading of response to chemo- and radiotherapy, aimed at developing a prognostic tool to guide postsurgical patient management. ${ }^{9-12}$ To date, these schemes have been based on the assessment of the amount of residual tumor, viability, tumor destruction, presence of mucin, and fibrosis. However, there is no international consensus as to which tumor response grading (TRG) system represents the best option. ${ }^{13}$ Indeed, there are many factors that make standardization difficult. First, the method and extent of tissue sampling is rarely specified and probably varies among studies. ${ }^{13}$ In addition, interobserver studies demonstrate poor concordance and a lack of precision and accuracy, calling into question the clinical utility of TRG systems. ${ }^{7}$

Therefore, further studies are needed to develop a reproducible and clinically relevant grading system based on prognostic markers validated for the neoadjuvant setting. The main objective of the present study is to identify objective parameters that predict prognostic value in PDAC patients resected after NACT and can be eventually incorporated into a prognostic index.

\section{PATIENTS AND METHODS}

\section{Study Population}

The study population consisted of 69 patients with nonmetastatic, resectable or borderline resectable ${ }^{14}$ cytologically confirmed PDAC who received primary combination NACT followed by surgical resection at our Institution between July 2005 and February 2016. To ensure homogeneity of eligibility criteria, treatment, staging and follow-up procedures, data collection and cleaning, only patients who were treated in the context of prospective clinical trials approved by the San Raffaele Scientific Institute Ethics Committee ${ }^{4,15-17}$ (Supplementary Table S1) were considered. We also included 36 patients who were underwent upfront surgery in order to comprehensively compare their histopathological features with patients treated with NACT. Of note, the upfront-surgery group included patients who were randomized in a neoadjuvant versus adjuvant trial ${ }^{4}$ and therefore represent an ideal comparator population because they were not selected on surgical outcome or postoperative recovery. Patients who received NACT were treated with anthracycline-containing $(n=50)$ or taxane-containing $(n=19)$ regimens for 3-6 months, according to the study design. On average, patients who received NACT underwent surgery 52.3 days (range 18-413 days) after the last chemotherapy administration.

\section{Morphological Evaluation}

All surgical specimens were examined and processed according to internal protocols of the pathology unit. The pancreaticoduodenectomy specimens were sampled with the bivalving approach through the common bile duct or by axial sections with en bloc inclusion of peripancreatic tissue. The distal pancreatectomy specimens were sampled by sectioning from the resection margin to the spleen. Total pancreatectomy specimens were sectioned at the level of the isthmus, and then the two halves were sampled as pancreaticoduodenectomy and distal pancreatectomy specimens, respectively. The "tumor bed" identified at the macroscopic level was included entirely and, since 2015, the entire pancreatic parenchyma was sampled. A median of 31 (range 11-81) formalin-fixed paraffin-embedded (FFPE) blocks were taken for each case.

All available slides were retrieved from the archive and reviewed by two expert pancreatic pathologists (M.S.L., C.D.) blinded to clinical information. FFPE blocks routinely sectioned at $4-5 \mu \mathrm{m}$ were stained with hematoxylin and eosin (H\&E). Slides were evaluated and assigned a score for each of the morphological parameters described below. Discordant scores were reviewed together under a 
multi-head microscope, and a final consensus between the two pathologists was reached for each case. For uniformity, all cases were reclassified according to the World Health Organization (WHO) Classification of Tumours-Digestive System Tumours, $2019^{18}$ and restaged according to the eighth edition (2017) of the Union for International Cancer Control (UICC) TNM classification. ${ }^{19}$ The presence of tumor at or within $1 \mathrm{~mm}$ of resection margin was assigned as a positive margin $(\mathrm{R} 1)^{20}$ for all pancreatic margins. The lymph node (LN) ratio was calculated as the ratio of positive $\mathrm{LN}$ divided by the total number of sampled LN.

A comprehensive histological assessment was performed evaluating 20 morphological parameters (Table S2). Briefly, dispersion described the residual adenocarcinoma cell distribution in the tumor bed ( 0 : single mass without dispersion; 1: sparse foci in adjacent samples; 2: sparse foci in distant samples) and regressive change described the cytological alterations of carcinoma cells ( 0 : absent; 1 : focally present; 2 : diffusely present), and neoplastic necrosis was similarly scored. The presence of precursor lesions such as pancreatic intraepithelial neoplasia (PanIN) and intraductal papillary mucinous neoplasm (IPMN) ${ }^{18}$ was assessed and graded as low grade versus high grade. ${ }^{17,21}$ Perineural, lymphovascular, and duodenal invasion by neoplastic cells were all evaluated and scored as dichotomous variables; 0 where absent and 1 when present at any level.

The tumor stroma was evaluated for the presence of keloid-like reaction, hyaline stroma, acellular mucin accumulation, dystrophic calcifications, and cellular stroma. The relationship between stroma and cellular neoplasia was scored according to the prevailing component within the tumor bed (score 1/stroma poor: neoplasia $\geq$ stroma; score $2 /$ stroma rich: stroma $>$ neoplasia). The presence of vascular wall alterations such as subintimal thickening, undulation of the inner elastic lamina, nonneoplastic thrombosis of the lumen, and changes of the muscular wall were evaluated. The presence of inflammatory cells was scored per cell type: granulocytes, macrophages, and lymphocytes; the latter, when forming architecturally distinct aggregates, were considered as tertiary lymphoid structures (TLS). An assessment of treatment response was also performed using the following published methods: Evans, ${ }^{10}$ College of American Pathologists (CAP), ${ }^{22}$ and M.D. Anderson ${ }^{23}$ tumor regression grading (TRG) systems.

\section{Statistical Analysis}

Disease-free survival (DFS) was defined as the time from treatment start to disease recurrence, death, or last follow-up for censored patient. Overall survival (OS) was defined as the time from treatment start to death or last follow-up for censored patients. Differences between the groups were evaluated using Fisher's exact test. Interobserver agreement was assessed using Cohen's kappa coefficient. The association between patient survival and morphological variables was investigated using the Cox proportional-hazards model on univariate analysis (COX$\mathrm{U})$.

To pre-select the clinical variables best associated with OS and DFS, a machine learning bootstrap-based method, built in the Matlab (v2020b) environment, was used. ${ }^{24}$ In short, the original sample was bootstrapped 1000 times and a COX-U was run for each sample bootstrapped and for each endpoint. The most significant variables occurring in each sample were ranked according to the frequency of their selection among the significantly predictive variables. Two models were developed for OS and DFS.

For each model, the most frequent variables at the top of bootstrap ranking procedure (variables with $p$-value $<0.05$ in more than 500 cases of the 1000 bootstrapped samples) were included in a Cox proportional-hazards model on backward multivariate analysis (COX-M) for the prediction of OS and DFS. A $p$-value $<0.20$ and a backward selection was set to retain variables in the model.

A prognostic index after neoadjuvant chemotherapy (PINC) was derived for each patient as the risk associated with the selected parameters according to the formula of the Cox regression:

$\mathrm{PINC}=B 0+\sum_{1}^{n} B n * X n$

where $\mathrm{Bn}$ are the coefficients of COX-M and $\mathrm{Xn}$ is the variables selected.

To represent the ability of the PINC in stratifying patients according to their OS and DFS, a cut-off value was derived as the best criterion according to the maximum value of the Youden index of the receiver operating characteristic (ROC) curve, having considered the OS and DFS as independent variables. PINC was then dichotomized as greater and smaller than the cut-off value, and finally the separation of the survival curves between the two groups was tested with the Kaplan-Meier test.

The performance of the models was quantified in terms of the area under the curve (AUC) of ROC curves, based on best cut-off according to the maximum value of the Youden index. Statistical analysis was performed in R (R Core Team, 2019) or MedCalc (v 20.008).

\section{RESULTS}

Between 2005 and 2016, 69 patients with resectable or borderline resectable PDAC received preoperative NACT (neoadjuvant group), while 36 patients with 
resectable PDAC underwent upfront resection and received postoperative adjuvant therapy (upfront-surgery group). More specifically, at diagnosis, patients with resectable PDAC were randomized to preoperative and postoperative PEXG (cisplatin, epirubicin, capecitabine, gemcitabine) (subgroup A), or to upfront surgery followed by adjuvant PEXG (subgroup B1) or gemcitabine (GEM) (subgroup B2). ${ }^{4}$ Patients with borderline resectable disease, based on historical period, received pre- and postoperative chemotherapy with either PEXG or PDXG (cisplatin, docetaxel, capecitabine, gemcitabine) ${ }^{15}$ (subgroup C) or pre- and postoperative chemotherapy with either PAXG (cisplatin, nab-paclitaxel, capecitabine, gemcitabine) ${ }^{16,17}$ or AG (nab-paclitaxel, gemcitabine) (subgroup D). ${ }^{17}$ Age and sex of patients were equal between the upfront-surgery and neoadjuvant groups, albeit males were overrepresented in subgroup A (Table 1). The distribution of morphological parameters evaluated was significantly different between the upfront-surgery (Groups B1 and B2) and neoadjuvant groups (Groups A, C, and D) (Table 2). Similar results were obtained by analyzing the subset of resectable PDAC patients alone, demonstrating the effect of NACT on tumor morphology (Table S3). The interobserver agreement of the morphological evaluation was substantial [kappa value: 0.72 (95\% CI 0.56-0.89)].

For the neoadjuvant group, the univariate analysis indicated LN involvement $(\mathrm{HR}=53.3 ; p<0.0001)$, necrosis $(\mathrm{HR}=3.31 ; p<0.0001)$, presence of perineural invasion $(\mathrm{HR}=2.81 ; p=0.006)$, high tumor grade $(\mathrm{HR}=2.09 ; p=0.025)$, duodenal invasion $(\mathrm{HR}=2.05$; $p=0.032)$, and positive resection margins $(\mathrm{HR}=1.99$; $p=0.04)$ as predictors of shorter OS. Conversely, high stroma-to-neoplasia ratio $(\mathrm{HR}=0.38 ; p=0.002)$, presence of dispersion ( $\mathrm{HR}=0.44 ; p=0.006)$, diffuse regressive changes $(\mathrm{HR}=0.39 ; p=0.013)$, and presence of mucin $(\mathrm{HR}=0.35 ; p=0.047)$ were positive prognostic factors. Similar results were obtained for DFS, with the addition of vascular invasion $(\mathrm{HR}=1.75 ; p=0.046)$ as a negative prognostic factor (Table 3 ).

On multivariate analysis for patients that received NACT, the predictors of shorter OS and DFS were perineural invasion and $\mathrm{LN}$ ratio, while high stroma to neoplasia ratio predicted longer OS and DFS (Fig. 1). According to the results of COX-M for OS and DFS, PINCs were computed as follows:

$$
\begin{aligned}
& \text { PINC_OS }=3.1318 \times \text { LN_Ratio }+0.7647 \\
& \quad \times \text { Perineural_invasion }-0.4788 \times \text { Stroma_Neoplasia_Ratio } \\
& \text { PINC_DFS }=2.1019 \times \text { LN_Ratio }+0.5173 \\
& \quad \times \text { Perineural_invasion }-0.5836 \times \text { Stroma_Neoplasia_Ratio }
\end{aligned}
$$

The PINC based on OS and DFS significantly distinguished patients with poor outcome from those with good outcome
( $p<0.0001$ and $p=0.0002$, respectively). Figure 2 shows the survival curves for OS and DFS after the stratification in the groups with good outcome (PINC_OS $<0.599$ and PINC_DFS $<-0.066$ ) and the groups with poor outcome (PINCs upper thresholds). The practical algorithm to calculate the PINC is summarized in Fig. 3.

Evans and CAP TRG systems showed a correlation between lower response rates with shorter OS and DFS. However, survival curves showed significant overlaps of the higher regression grades for each system (Figs. S1, S2). Similarly, no correlation was found between M.D. Anderson TRG scores and patient prognosis (Fig. S3).

\section{DISCUSSION}

Growing evidence endorses the use of NACT on patients diagnosed with resectable PDAC compared with upfront surgery, with a possible increase in both DFS and OS. ${ }^{4}$ Indeed, clinical practice is increasingly shifting from a direct surgical approach to a systemic treatment strategy since the priority is to block early metastatic dissemination rather than remove the primary tumor. Consequently, the number of patients undergoing surgery after NACT is expected to increase in the near future. An objective and reproducible histopathologic evaluation of surgical specimens after NACT could play a pivotal role in providing an assessment of therapy-related effects, allowing intertrial comparisons and guiding postoperative treatment choice based on best evidence. Moreover, should a relationship between pathologic response and outcome be demonstrated, the classification would also provide prognostic information and stratify patients in future prospective trials. In addition, a reliable pathologic prognostic index may allow the clustering of patients into different groups of clinical relevance.

Currently, multiple tumor response scoring systems have been proposed, ${ }^{25}$ of which the most widely used in the literature are the Evans, ${ }^{10}$ College of American Pathologists (CAP), ${ }^{22}$ and M.D. Anderson ${ }^{23}$ scoring systems. However, no standardization has yet been achieved in clinical practice. Indeed, the lack of consensus on which score represents best practice, interobserver variability, and reproducibility is a major challenge in the pathologic assessment of response after NACT. Some studies have evaluated the reproducibility of the available grading systems, highlighting a lack of precision, low degree of concordance, and no correlation with prognosis in independent cohorts. $^{23,26-28}$ Furthermore, current response scoring systems do not provide prognostic stratification outside the rare situations of a complete or near complete response. $^{23,26}$ In the current study, none of these TRG systems predicted DFS and OS (Figs. S1, S2, S3). 
TABLE 1 Baseline characteristics

\begin{tabular}{|c|c|c|c|c|c|}
\hline \multirow[t]{2}{*}{ Therapy } & \multicolumn{2}{|c|}{ Upfront-surgery group $(N=36)$} & \multicolumn{3}{|c|}{ Neoadjuvant group $(N=69)$} \\
\hline & $\begin{array}{l}\text { Adjuvant PEXG Group } \\
\text { B1 }(N=20)\end{array}$ & $\begin{array}{l}\text { Adjuvant GEM Group } \\
\text { B2 }(N=16)\end{array}$ & $\begin{array}{l}\text { Neoadjuvant PEXG } \\
\text { Group A }(N=18)\end{array}$ & $\begin{array}{l}\text { Primary PEXG/PDGX } \\
\text { Group C }(N=32)\end{array}$ & $\begin{array}{l}\text { Primary PAXG } \\
\text { Group D }(N=19)\end{array}$ \\
\hline \multicolumn{6}{|l|}{ Sex } \\
\hline Male & $10(50 \%)$ & $9(57 \%)$ & $15(84 \%)$ & $17(53 \%)$ & $9(47 \%)$ \\
\hline Female & $10(50 \%)$ & $7(43 \%)$ & $3(16 \%)$ & $15(47 \%)$ & $10(53 \%)$ \\
\hline Age, years & $69(50-75)$ & $67(37-74)$ & $66(46-76)$ & $65(41-74)$ & $69(51-76)$ \\
\hline \multicolumn{6}{|c|}{ Tumor location } \\
\hline Head & $16(80 \%)$ & $14(87 \%)$ & $15(83 \%)$ & $25(78 \%)$ & $14(74 \%)$ \\
\hline $\begin{array}{l}\text { Body or } \\
\text { tail }\end{array}$ & $3(15 \%)$ & $1(6.5 \%)$ & $3(17 \%)$ & $5(16 \%)$ & $5(26 \%)$ \\
\hline $\begin{array}{l}\text { Head } \\
\text { and } \\
\text { body }\end{array}$ & $1(5 \%)$ & $1(6.5 \%)$ & 0 & $1(3 \%)$ & 0 \\
\hline $\begin{array}{l}\text { Head } \\
\text { and tail }\end{array}$ & 0 & 0 & 0 & $1(3 \%)$ & 0 \\
\hline \multicolumn{6}{|l|}{ Tumor } \\
\hline pT1a & 0 & 0 & $1(6 \%)$ & $1(3 \%)$ & 0 \\
\hline pT1b & 0 & 0 & $2(11 \%)$ & $3(10 \%)$ & $1(5 \%)$ \\
\hline pT1c & $10(50 \%)$ & $2(12 \%)$ & $8(44 \%)$ & $8(25 \%)$ & $7(37 \%)$ \\
\hline pT2 & $6(30 \%)$ & $12(76 \%)$ & $6(33 \%)$ & $17(53 \%)$ & $8(42 \%)$ \\
\hline pT3 & $4(20 \%)$ & $2(12 \%)$ & $1(6 \%)$ & $1(3 \%)$ & $1(5 \%)$ \\
\hline NA & 0 & 0 & 0 & $2(6 \%)$ & $2(11 \%)$ \\
\hline \multicolumn{6}{|l|}{ Grade } \\
\hline G1 & 0 & $1(6 \%)$ & $1(5 \%)$ & $2(6 \%)$ & 0 \\
\hline $\mathrm{G} 2$ & $8(40 \%)$ & $5(31 \%)$ & $12(67 \%)$ & $15(47 \%)$ & $15(79 \%)$ \\
\hline G3 & $12(60 \%)$ & $10(63 \%)$ & $5(28 \%)$ & $12(37 \%)$ & $2(11 \%)$ \\
\hline NA & 0 & 0 & 0 & $3(10 \%)$ & $2(11 \%)$ \\
\hline \multicolumn{6}{|l|}{ Nodes } \\
\hline No & $5(25 \%)$ & $4(25 \%)$ & $10(55 \%)$ & $13(41 \%)$ & $11(58 \%)$ \\
\hline N1 & $8(40 \%)$ & $4(25 \%)$ & $3(17 \%)$ & $12(37 \%)$ & $7(37 \%)$ \\
\hline $\mathrm{N} 2$ & $7(35 \%)$ & $8(50 \%)$ & $5(28 \%)$ & $6(19 \%)$ & $1(5 \%)$ \\
\hline NA & 0 & 0 & 0 & $1(3 \%)$ & 0 \\
\hline \multicolumn{6}{|c|}{ Resection margin } \\
\hline R0 & $9(45 \%)$ & $2(12 \%)$ & $12(67 \%)$ & $6(19 \%)$ & $6(32 \%)$ \\
\hline $\mathrm{R} 1$ & $11(55 \%)$ & $14(88 \%)$ & $6(33 \%)$ & $26(81 \%)$ & $13(68 \%)$ \\
\hline
\end{tabular}

Sex, age, and tumor location are reported at the time of NACT or surgery. Tumor factor, grade, nodal involvement, and resection margin are evaluated on the histology. PEXG cisplatin, epirubicin, capecitabine, gemcitabine, GEM gemcitabine, PDGX cisplatin, docetaxel, capecitabine, gemcitabine, $P A X G$ cisplatin, nab-paclitaxel, capecitabine, gemcitabine

These scoring systems are based either on the amount of treatment-related fibrosis compared with residual tumor or, alternatively, on the proportion of viable residual tumor compared with the size of tumor bed. In other organs, fibrosis is exploited as a biomarker of response to therapy in different grading systems. ${ }^{29,30}$ However, chemo-naïve PDAC is often associated with an inherent extensive desmoplastic stromal reaction that is almost indistinguishable from therapy-induced fibrosis. ${ }^{31}$ Fibrosis may also be due to associated pancreatitis or be secondary to obstructive ductal changes induced by the tumor mass. In fact, as emerged from a survey conducted among 23 pancreatic pathologists from 4 continents, $87 \%$ believed that the amount of fibrosis in comparison to the extent of viable tumor was not a reliable scoring criterion. ${ }^{13}$

In the present work, we performed a comprehensive characterization of the morphological differences presenting in patients who received NACT compared with those 
TABLE 2 Morphological features of histological specimens of patients of either neoadjuvant or surgical group

\begin{tabular}{llll}
\hline Characteristic & Neoadjuvant & Upfront surgery & $p$-Value $^{\mathrm{a}}$ \\
& $N(\%)$ & $N(\%)$ & \\
\hline
\end{tabular}

\begin{tabular}{llll}
\hline Grade $^{\wedge}$ & & & \\
G2 & $42(68.9)$ & $13(37.1)$ & \\
G3 & $19(31.1)$ & $22(62.9)$ & $\mathbf{0 . 0 0 3}$
\end{tabular}

\section{Nodes}

pNO

$\mathrm{pN} 1$

$\mathrm{pN} 2$

$$
34(50)
$$$$
9(25)
$$

Dispersion

Absent

$$
22 \text { (32.4) }
$$$$
13 \text { (36.1) }
$$

Present

24 (34.8)

$14(38.9)$

$31(86.1)$

Stroma/Neoplasia ratio

Neoplasia $\geq$ stroma

Stroma $>$ neoplasia

$20(29.4)$

$5(13.9)$

Vascular invasion

Absent

Present

39 (56.5)

30 (83.3)

6 (16.7)

7 (19.4)

\begin{tabular}{|c|c|c|c|}
\hline Absent & $48(69.6)$ & $11(30.6)$ & \\
\hline Present & $21(30.4)$ & $25(69.4)$ & 0.0002 \\
\hline \multicolumn{4}{|c|}{ Hyaline fibrosis } \\
\hline Absent & $17(24.6)$ & $25(69.4)$ & \\
\hline Present & $52(75.4)$ & $11(30.6)$ & $<\mathbf{0 . 0 0 0 1}$ \\
\hline \multicolumn{4}{|c|}{ Necrosis } \\
\hline Absent & $55(79.7)$ & $21(58.3)$ & \\
\hline Present & $14(20.3)$ & $15(41.7)$ & 0.023 \\
\hline \multicolumn{4}{|c|}{ Vascular wall alterations } \\
\hline Absent & $2(2.9)$ & $7(19.4)$ & \\
\hline Present & $67(97.1)$ & $29(80.6)$ & 0.0072 \\
\hline \multicolumn{4}{|c|}{ Stromal calcification } \\
\hline Absent & $57(82.6)$ & $36(100)$ & \\
\hline Present & $12(17.4)$ & $0(0)$ & 0.007 \\
\hline \multicolumn{4}{|c|}{ Regressive changes } \\
\hline Absent & $25(36.2)$ & $33(92)$ & \\
\hline Focal & $21(30.4)$ & $3(8)$ & \\
\hline Diffuse & $23(33.4)$ & $0(0)$ & $<0.0001$ \\
\hline \multicolumn{4}{|c|}{ Cellular stroma } \\
\hline Absent & $51(73.9)$ & $20(55.6)$ & \\
\hline Present & $18(26.1)$ & $16(44.4)$ & 0.078 \\
\hline \multicolumn{4}{|c|}{ PanIN/IPMN } \\
\hline Absent & $18(26.5)$ & $4(11.1)$ & \\
\hline Present & $50(73.5)$ & $32(88.9)$ & 0.081 \\
\hline \multicolumn{4}{|l|}{ TLS } \\
\hline Absent & $53(76.8)$ & $32(88.9)$ & \\
\hline Present & $16(23.2)$ & $4(11.1)$ & 0.19 \\
\hline \multicolumn{4}{|c|}{ Macrophages } \\
\hline Absent & $41(59.4)$ & $26(72.2)$ & \\
\hline Present & $28(40.6)$ & $10(27.8)$ & 0.2 \\
\hline
\end{tabular}

Granulocytes

\begin{tabular}{|c|c|c|c|}
\hline Characteristic & $\begin{array}{l}\text { Neoadjuvant } \\
N(\%)\end{array}$ & $\begin{array}{l}\text { Upfront surgery } \\
N(\%)\end{array}$ & $p$-Value ${ }^{\mathrm{a}}$ \\
\hline \multicolumn{4}{|c|}{ Perineural invasion } \\
\hline Absent & $20(29)$ & $6(16.7)$ & \\
\hline Present & $49(71)$ & $30(83.3)$ & 0.23 \\
\hline \multicolumn{4}{|l|}{ Lymphocytes } \\
\hline Absent & $23(33.3)$ & $16(44.4)$ & \\
\hline Present & $46(66.7)$ & $20(55.6)$ & 0.29 \\
\hline \multicolumn{4}{|c|}{ Duodenal invasion* } \\
\hline Absent & $28(51)$ & $13(40)$ & \\
\hline Present & $27(49)$ & $20(60)$ & 0.38 \\
\hline \multicolumn{4}{|l|}{ Mucin } \\
\hline Absent & $59(85.5)$ & $32(88.9)$ & \\
\hline Present & $10(14.5)$ & $4(11.1)$ & 0.77 \\
\hline \multicolumn{4}{|c|}{ Resection margin } \\
\hline R0 & $24(34.8)$ & $11(30.6)$ & \\
\hline $\mathrm{R} 1$ & $45(65.2)$ & $25(69.4)$ & 0.82 \\
\hline \multicolumn{4}{|c|}{ Keloid stromal reaction } \\
\hline Absent & $41(59.4)$ & $22(61.1)$ & \\
\hline Present & $28(40.6)$ & $14(38.9)$ & $>0.9$ \\
\hline
\end{tabular}

Table 2 (continued)

PanIN pancreatic intraepithelial neoplasia, IPMN intraductal papillary mucinous neoplasm, TLS tertiary lymphoid structure

${ }^{\mathrm{a}}$ Fisher's exact test, $p<0.05 .{ }^{\wedge} \mathrm{G} 1$ were excluded from the analysis

${ }^{*}$ Not evaluated for distal pancreatectomy specimens

who underwent upfront surgery, using 20 different histologic parameters (Table S2). The statistically significant differences in the distribution of numerous morphological parameters between neoadjuvant and upfront surgery patients (Table 2) suggest that chemotherapy caused radical changes in tumor morphology, even though none of these features can be exclusively correlated with the effect of chemotherapy. Therefore, we considered a paradigm shift in the evaluation of patients who received neoadjuvant treatment. Those parameters that were able to predict prognosis after NACT and relatively objective to evaluate were incorporated into a meaningful prognostic index.

Multivariate analysis showed that LN involvement, perineural invasion, and the ratio between residual tumor cells and stroma correlated significantly with patient prognosis. $\mathrm{LN}$ involvement was described as a quantitative parameter, calculated as the ratio of positive $\mathrm{LN}$ over the total number of sampled LN. Perineural invasion was categorized as a dichotomous variable of absent versus present. The ratio between stroma and residual tumor was based on a qualitative evaluation of the area covered by the two components. In this model, the variable was stratified in two levels: stroma rich tumors, where fibrosis predominated, and stroma poor tumors, where neoplastic cells 
TABLE 3 Univariate Cox regression analysis

\begin{tabular}{|c|c|c|c|c|c|c|c|c|}
\hline \multirow[t]{2}{*}{ Characteristic } & \multicolumn{4}{|c|}{ Disease-free survival } & \multicolumn{4}{|c|}{ Overall survival } \\
\hline & $N$ & HR & $95 \% \mathrm{CI}$ & $p$-Value & $N$ & HR & $95 \% \mathrm{CI}$ & $p$-Value \\
\hline $\begin{array}{l}\text { Resection margin } \\
\text { R0 }\end{array}$ & 68 & & & & 69 & & & \\
\hline $\mathrm{R} 1$ & & 1.69 & $0.92,3.1$ & 0.088 & & 1.99 & $1.03,3.85$ & 0.040 \\
\hline $\begin{array}{l}\text { Duodenal invasion* } \\
\text { Absent }\end{array}$ & 55 & & & & 55 & & & \\
\hline Present & & 2.12 & $1.12,4.01$ & 0.021 & & 2.05 & $1.06,3.94$ & $\mathbf{0 . 0 3 2}$ \\
\hline $\begin{array}{l}\text { Grade }^{\wedge} \\
\text { G2 }\end{array}$ & 60 & & & & 61 & & & \\
\hline G3 & & 1.66 & $0.9,3.07$ & 0.1 & & 2.09 & $1.10,3.97$ & 0.025 \\
\hline $\begin{array}{l}\text { Perineural invasion } \\
\text { Absent }\end{array}$ & 68 & & & & 69 & & & \\
\hline Present & & 2.23 & $1.16,4.3$ & 0.016 & & 2.81 & $1.35,5.86$ & 0.006 \\
\hline $\begin{array}{r}\text { Necrosis } \\
\text { Absent }\end{array}$ & 68 & & & & 69 & & & \\
\hline Present & & 2.4 & $1.25,4.61$ & 0.008 & & 3.31 & $1.73,6.37$ & $<0.001$ \\
\hline $\begin{array}{c}\text { Nodes } \\
\text { pN0 }\end{array}$ & 67 & & & & 68 & & & \\
\hline $\mathrm{pN} 1$ & & 2.04 & $1.07,3.88$ & 0.029 & & 2.57 & $1.30,5.07$ & 0.006 \\
\hline $\mathrm{pN} 2$ & & 3.08 & $1.47,6.43$ & 0.003 & & 2.51 & $1.18,5.33$ & 0.017 \\
\hline $\mathrm{LN}$ ratio & 67 & 17.9 & $3.26,97.9$ & $<\mathbf{0 . 0 0 1}$ & 68 & 53.3 & $7.60,374$ & $<0.001$ \\
\hline $\begin{array}{l}\text { Mucin } \\
\text { Absent }\end{array}$ & 69 & & & & 69 & & & \\
\hline Present & & 0.37 & $0.15,0.94$ & 0.036 & & 0.35 & $0.13,0.99$ & 0.047 \\
\hline $\begin{array}{l}\text { Regressive changes } \\
\text { Absent }\end{array}$ & 69 & & & & 69 & & & \\
\hline Focal & & 0.64 & $0.33,1.23$ & 0.2 & & 0.71 & $0.37,1.37$ & 0.3 \\
\hline Diffuse & & 0.48 & $0.15,0.94$ & 0.033 & & 0.39 & $0.18,0.82$ & 0.013 \\
\hline $\begin{array}{l}\text { Dispersion } \\
\text { Absent }\end{array}$ & 68 & & & & 69 & & & \\
\hline Present & & 0.54 & $0.31,0.95$ & 0.031 & & 0.44 & $0.24,0.78$ & 0.006 \\
\hline $\begin{array}{c}\text { Stroma/Neoplasia Ratio } \\
\text { Neoplasia } \geq \text { Stroma }\end{array}$ & 68 & & & & 68 & & & \\
\hline Stroma $>$ Neoplasia & & 0.5 & $0.28,0.9$ & 0.021 & & 0.38 & $0.21,0.70$ & 0.002 \\
\hline $\begin{array}{l}\text { Macrophages } \\
\text { Absent }\end{array}$ & 68 & & & & 69 & & & \\
\hline Present & & 1.23 & $0.71,2.14$ & 0.5 & & 1.39 & $0.77,2.51$ & 0.3 \\
\hline $\begin{array}{l}\text { Vascular invasion } \\
\text { Absent }\end{array}$ & 68 & & & & 69 & & & \\
\hline Present & & 1.75 & $1.01,3.02$ & 0.046 & & 1.65 & $0.93,2.94$ & 0.086 \\
\hline $\begin{array}{l}\text { Vascular wall alterations } \\
\text { Absent }\end{array}$ & 68 & & & & 69 & & & \\
\hline Present & & 0.42 & $0.1,1.77$ & 0.2 & & 0.28 & $0.07,1.18$ & 0.083 \\
\hline $\begin{array}{l}\text { PanIN/IPMN } \\
\text { Absent }\end{array}$ & 67 & & & & 68 & & & \\
\hline Present & & 0.76 & $0.41,1.4$ & 0.4 & & 0.68 & $0.35,1.29$ & 0.2 \\
\hline
\end{tabular}


Table 3 (continued)

\begin{tabular}{|c|c|c|c|c|c|c|c|c|}
\hline \multirow[t]{2}{*}{ Characteristic } & \multicolumn{4}{|c|}{ Disease-free survival } & \multicolumn{4}{|c|}{ Overall survival } \\
\hline & $N$ & HR & $95 \% \mathrm{CI}$ & $p$-Value & $N$ & HR & $95 \% \mathrm{CI}$ & $p$-Value \\
\hline $\begin{array}{l}\text { Keloid stromal reaction } \\
\text { Absent }\end{array}$ & 68 & & & & 69 & & & \\
\hline Present & & 0.9 & $0.51,1.56$ & 0.7 & & 0.83 & $0.47,1.49$ & 0.5 \\
\hline $\begin{array}{l}\text { Hyaline fibrosis } \\
\text { Absent }\end{array}$ & 68 & & & & 69 & & & \\
\hline Present & & 0.71 & $0.38,1.34$ & 0.3 & & 0.64 & $0.33,1.22$ & 0.2 \\
\hline $\begin{array}{l}\text { Cellular stroma } \\
\text { Absent }\end{array}$ & 68 & & & & 69 & & & \\
\hline Present & & 1.32 & $0.72,2.44$ & 0.4 & & 1.47 & $0.76,2.86$ & 0.3 \\
\hline $\begin{array}{l}\text { TLS } \\
\text { Absent }\end{array}$ & 68 & & & & 69 & & & \\
\hline Present & & 1.8 & $0.97,3.34$ & 0.063 & & 1.84 & $0.92,3.67$ & 0.084 \\
\hline $\begin{array}{l}\text { Lymphocytes } \\
\text { Absent }\end{array}$ & 68 & & & & 69 & & & \\
\hline Present & & 0.95 & $0.54,1.96$ & 0.9 & & 1.01 & $0.55,1.83$ & $>0.9$ \\
\hline $\begin{array}{l}\text { Granulocytes } \\
\text { Absent }\end{array}$ & 68 & & & & 69 & & & \\
\hline Present & & 1.63 & $0.92,2.9$ & 0.093 & & 1.52 & $0.84,2.76$ & 0.2 \\
\hline $\begin{array}{l}\text { Stromal calcification } \\
\text { Absent }\end{array}$ & 69 & & & & 69 & & & \\
\hline Present & & 0.90 & $0.44,1.85$ & 0.8 & & 0.97 & $0.45,2.09$ & $>0.9$ \\
\hline
\end{tabular}

$H R$ hazard ratio, $C I$ confidence interval, $L N$ ratio lymph nodes ratio, PanIN pancreatic intraepithelial neoplasia, IPMN intraductal papillary mucinous neoplasm, $T L S$ tertiary lymphoid structure

${ }^{\wedge} \mathrm{G} 1$ were excluded from the analysis. *Not evaluated for distal pancreatectomy specimens

were equally or more represented than the stromal component. To increase reproducibility, immunostaining of tumor cells and stromal components could be implemented to perform quantitative evaluation of the stroma-to-neoplasia ratio by a simple method of automated immunohistochemistry image analysis. Necrosis was excluded from the grading scheme because of the difficulty in distinguishing treatment-related necrosis from tumor necrosis.

Although the current analysis was carried out on a limited number of patients, relevant morphological features have already been correlated with prognosis, further reinforcing the present findings. For instance, perineural invasion is known to be involved in PDAC dissemination at distant organs, and correlates with poor prognosis. ${ }^{32} \mathrm{LN}$ involvement is part of the TNM scoring system and is a well-established prognostic factor. However, LN ratio may be more informative compared with the TNM classification, ${ }^{33}$ even though it may be affected by the total number of LN sampled and assessed. In the present study, 25 nodes (range 5-78) were evaluated on average. Indeed, we confirmed that LN ratio has the strongest association with both DFS and OS in our cohort.
The novelty of the present classification is that perineural invasion, $\mathrm{LN}$ ratio, and stroma-to-neoplasia ratio were combined to generate a comprehensive tumor regression scoring system that can be easily translated into clinical practice. Results of our multivariate analysis have been used to generate a prognostic index (PINC), based on the linear combination of Cox coefficients of the selected variables multiplied by the values of the respective variables in the population, thus weighting the influence of each parameter in the formula. The resulting best threshold was applied to stratify the cohort and significantly distinguished patients with good versus poor prognosis.

Despite the promising results, this study has some limitations. First, the number of patients was relatively small over a long time span (2005-2016). Second, different and noncanonical neoadjuvant regimens were used. Because of the limited number of cases, we could not determine the effect of each regimen. Nevertheless, our intent was to create a universal prognostic score that was independent of the chemotherapy regimen. Furthermore, by comparing the distribution of morphological parameters among the different therapeutic subgroups of the neoadjuvant group, we did not identify major differences. To verify the robustness 
(a)

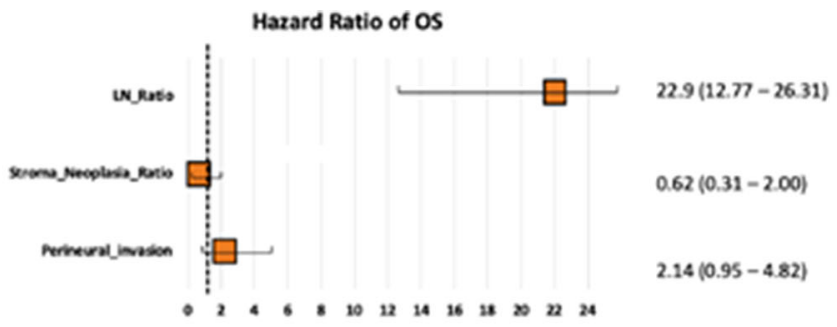

(b)

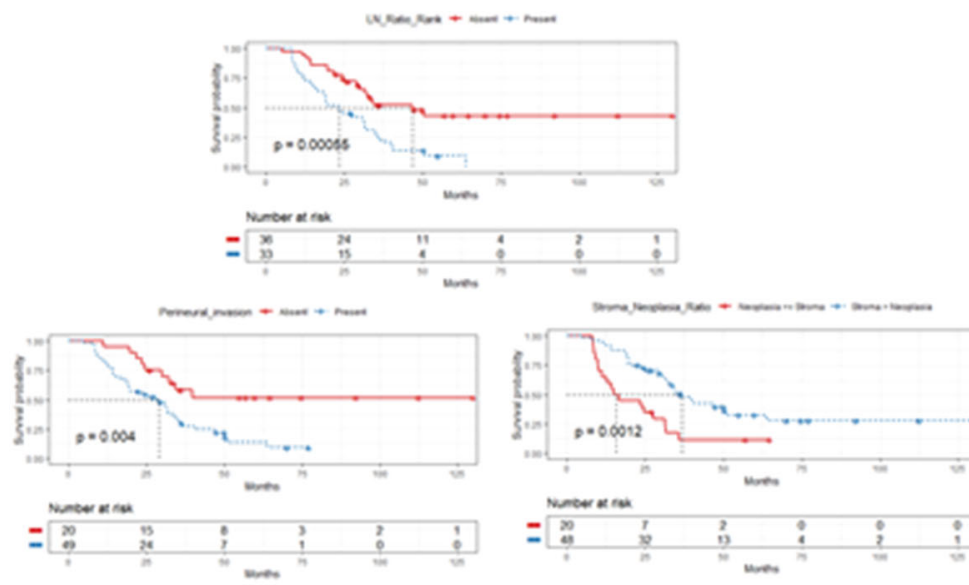

(c)

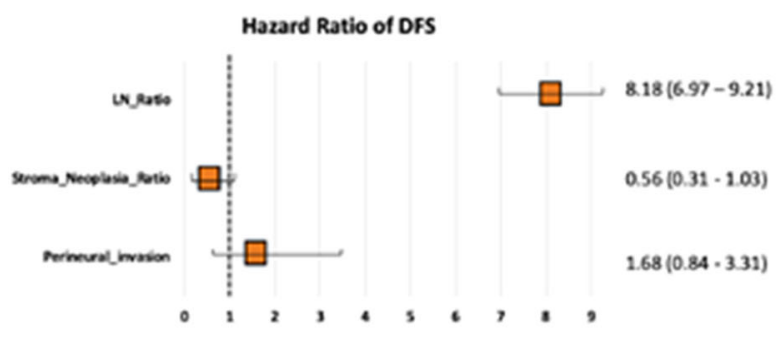

(d)
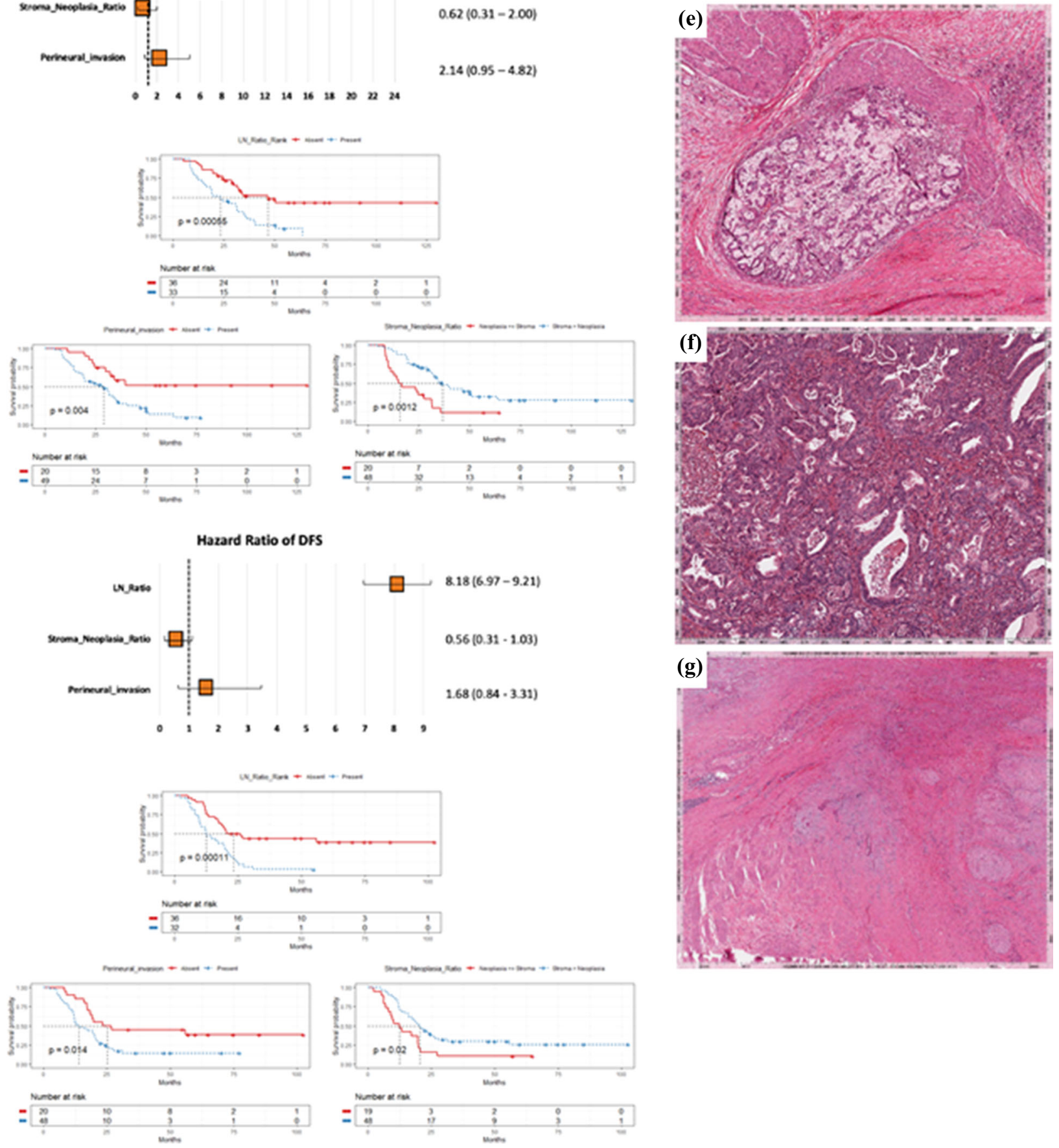

FIG. 1 Multivariate Cox proportional hazard model of OS and DFS of patients belonging to neoadjuvant group. (A) Forest plot of multivariate analysis based on OS. (B) Kaplan-Meier curves of the significant predictive categorical variables based on OS. (C) Forest plot of multivariate analysis based on DFS. (D) Kaplan-Meier curves

of the PINC, a validation study on a larger cohort of patients will be carried out. In addition, it will be applied in a retrospective series of patients treated with of the significant predictive categorical variables based on DFS. (E) Representative image of peri- and endoneural invasion. (F) Representative image of stroma-poor tumor. (G) Representative image of stroma-rich tumor

FOLFIRINOX and in the context of a multicenter, prospective clinical trial led by our institution (PACT-21 trial; NCT04793932). The trial will enroll more than 250 
FIG. 2 Kaplan-Meier curves based on the prognostic index after neoadjuvant chemotherapy (PINC). (A) Based on overall survival (log-rank test, $p<0.0001)$. (B) Based on disease-free survival (log-rank test, $p<0.0002$ ). $0=$ low risk population, $1=$ high risk population. The $x$-axis represents the months of OS (left panel) or DFS (right panel)

Lymph nodes ratio

Positive nodes Total nodes

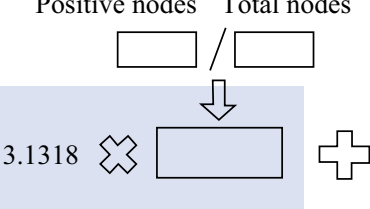

(a)

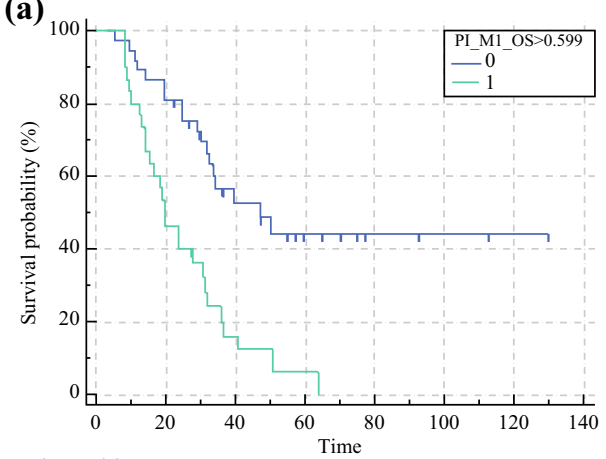

Number at risk

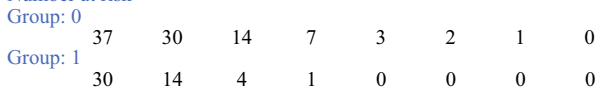

(b)

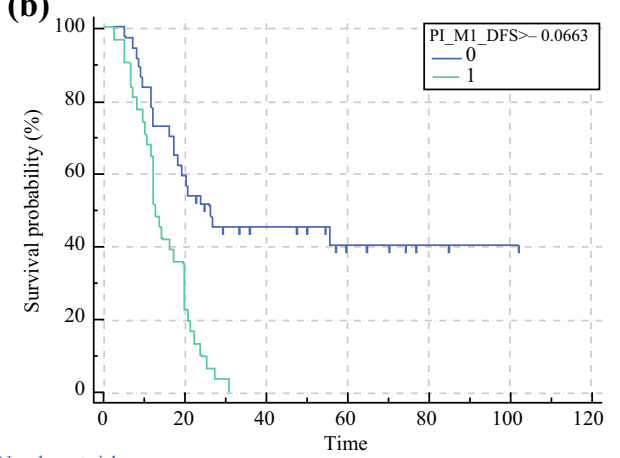

Number at risk

Group: 0

Group: 1

$22 \quad 12$

6

$2-1 \quad 0$

$0 \quad 0 \quad 0$

FIG. 3 Scheme of the algorithm for determining PINC based on OS

patients with resectable or borderline resectable pancreatic cancer that will receive NACT followed by surgery, allowing the evaluation of effective prognostic reliability in a real-life clinical setting and interobserver reproducibility across different centers of the PINC.

In conclusion, the PINC proposed in the current study is mostly quantitative in nature, easy to use, and may represent a reliable tumor regression grading system to predict patient outcomes after NACT followed by surgery for PDAC.

Supplementary Information The online version contains supplementary material available at https://doi.org/10.1245/s10434022-11413-7.

\section{ACKNOWLEDGEMENT None.}

FUNDING This study was partially supported by MyEverest ONLUS. The funders of the study had no role in the study design, data collection, data analysis, data interpretation, or writing of the report.

DISCLOSURES M. Reni reports grants, personal fees, and nonfinancial support from Celgene (a Bristol-Myers Squibb Company), Baxalta, Shire, Eli Lilly and Company, Pfizer, Novocure, Novartis, MSD, AstraZeneca, Sanofi, Baxter, Servier, SOTIO, and Boston Pharmaceuticals. M.F. reports grants from Novartis/AAA.

OPEN ACCESS This article is licensed under a Creative Commons Attribution 4.0 International License, which permits use, sharing, adaptation, distribution and reproduction in any medium or format, as long as you give appropriate credit to the original author(s) and the source, provide a link to the Creative Commons licence, and indicate if changes were made. The images or other third party material in this article are included in the article's Creative Commons licence, unless indicated otherwise in a credit line to the material. If material is not included in the article's Creative Commons licence and your intended use is not permitted by statutory regulation or exceeds the permitted use, you will need to obtain permission directly from the copyright holder. To view a copy of this licence, visit http://creativecommons. org/licenses/by/4.0/.

\section{REFERENCES}

1. Bray F, Ferlay J, Soerjomataram I, Siegel RL, Torre LA, Jemal A. Global cancer statistics 2018: GLOBOCAN estimates of incidence and mortality worldwide for 36 cancers in 185 countries. CA Cancer J Clin. 2018;68(6):394-424. https://doi.org/10. 3322/caac.21492.

2. Kim YI, Song KB, Lee YJ, et al. Management of isolated recurrence after surgery for pancreatic adenocarcinoma. $\mathrm{Br} J$ Surg. 2019;106(7):898-909. https://doi.org/10.1002/bjs.11144.

3. Tempero MA, Reni M, Riess H, et al. APACT: phase III, multicenter, international, open-label, randomized trial of adjuvant nab-paclitaxel plus gemcitabine (nab-P/G) vs gemcitabine (G) for surgically resected pancreatic adenocarcinoma. J Clin Oncol. 2019;37(15_suppl):4000. https://doi.org/10.1200/JCO.2019.37.1 5_suppl.4000.

4. Reni M, Balzano G, Zanon S, et al. Safety and efficacy of preoperative or postoperative chemotherapy for resectable pancreatic adenocarcinoma (PACT-15): a randomised, open-label, phase 2-3 trial. Lancet Gastroenterol Hepatol. 2018;3(6):413-23. http s://doi.org/10.1016/S2468-1253(18)30081-5.

5. Motoi F, Kosuge T, Ueno H, et al. Randomized phase II/III trial of neoadjuvant chemotherapy with gemcitabine and S-1 versus 
upfront surgery for resectable pancreatic cancer (Prep-02/ JSAP05). Jpn J Clin Oncol. 2019;49(2):190-4. https://doi.org/10. 1093/jjco/hyy 190.

6. Tempero MA, Malafa MP, Al-Hawary M, et al. Pancreatic adenocarcinoma, version 2.2017: Clinical practice guidelines in Oncology. JNCCN J Natl Compr Cancer Netw. 2017;15(8):1028-61. https://doi.org/10.6004/jnccn.2017.0131.

7. Kalimuthu SN, Serra S, Dhani N, Chetty R. The spectrum of histopathological changes encountered in pancreatectomy specimens after neoadjuvant chemoradiation, including subtle and less-well-recognised changes. J Clin Pathol. 2016;69(6):463-71. https://doi.org/10.1136/jclinpath-2016-203604.

8. Schorn S, Demir IE, Reyes CM, et al. The impact of neoadjuvant therapy on the histopathological features of pancreatic ductal adenocarcinoma-a systematic review and meta-analysis. Cancer Treat Rev. 2017;55:96-106. https://doi.org/10.1016/j.ctrv.2017.03.003.

9. Ishikawa $\mathrm{O}$, Ohhigashi $\mathrm{H}$, Teshima $\mathrm{T}$, et al. Clinical and histopathological appraisal of preoperative irradiation for adenocarcinoma of the pancreatoduodenal region. J Surg Oncol. 1989;40(3):143-51. https://doi.org/10.1002/jso.2930400303.

10. Evans DB, Rich TA, Byrd DR, et al. Preoperative chemoradiation and pancreaticoduodenectomy for adenocarcinoma of the pancreas. Arch Surg. 1992;127(11):1335-9. https://doi.org/10.1001/a rchsurg.1992.01420110083017.

11. Pendurthi TK, Hoffman JP, Ross E, Johnson DE, Eisenberg BL. Preoperative versus postoperative chemoradiation for patients with resected pancreatic adenocarcinoma. Am Surg. 1998;64(7):686-92.

12. Hartman DJ, Krasinskas AM. Assessing treatment effect in pancreatic cancer. Arch Pathol Lab Med. 2012;136(1):100-9. h ttps://doi.org/10.5858/arpa.2011-0144-RA.

13. Janssen BV, Tutucu F, van Roessel S, et al. Amsterdam International Consensus Meeting: tumor response scoring in the pathology assessment of resected pancreatic cancer after neoadjuvant therapy. Mod Pathol. 2021;34(1):4-12. https://doi.org/10. 1038/s41379-020-00683-9.

14. Bockhorn M, Uzunoglu FG, Adham M, et al. Borderline resectable pancreatic cancer: a consensus statement by the International Study Group of Pancreatic Surgery (ISGPS). Surgery. 2014;155(6):977-88. https://doi.org/10.1016/j.surg.2014.02.001.

15. Reni M, Balzano G, Zanon S, et al. Phase 1B trial of Nab-paclitaxel plus gemcitabine, capecitabine, and cisplatin (PAXG regimen) in patients with unresectable or borderline resectable pancreatic adenocarcinoma. $\mathrm{Br} J$ Cancer. 2016;115(3):290-6. https://doi.org/10.1038/bjc.2016.209.

16. Reni M, Cereda S, Rognone A, et al. A randomized phase II trial of two different 4-drug combinations in advanced pancreatic adenocarcinoma: cisplatin, capecitabine, gemcitabine plus either epirubicin or docetaxel (PEXG or PDXG regimen). Cancer Chemother Pharmacol. 2012;69(1):115-23. https://doi.org/10.10 07/s00280-011-1680-2.

17. Reni M, Zanon S, Balzano G, et al. A randomised phase 2 trial of nab-paclitaxel plus gemcitabine with or without capecitabine and cisplatin in locally advanced or borderline resectable pancreatic adenocarcinoma. Eur J Cancer. 2018;102:95-102. https://doi.or g/10.1016/j.ejca.2018.07.007.

18. WHO. WHO Classification of the digestive system. 5th edn (WHO Classification of Tumours Editorial Board, ed.). Lyon: IARC Press; 2019.

19. Brierley JD, Gospodarowicz MK, Wittekind C editors. TNM classification of malignant tumours. 8th edn. Hoboken: Wiley; 2017.

20. Verbeke C, Löhr M, Severin Karlsson J, Del Chiaro M. Pathology reporting of pancreatic cancer following neoadjuvant therapy: challenges and uncertainties. Cancer Treat Rev. 2015;41(1):17-26. https://doi.org/10.1016/j.ctrv.2014.11.002.

21. Basturk O, Hong S-M, Wood LD, et al. A revised classification system and recommendations from the Baltimore Consensus Meeting for Neoplastic Precursor Lesions in the Pancreas. Am J Surg Pathol. 2015;39(12):1730-41. https://doi.org/10.1097/PAS. 0000000000000533.

22. Washington KBJ, Berlin J, Branton P, Burgart LJ, Carter DK, Compton CCFP, et al. Protocol for the examination of specimens from patients with carcinoma of the exocrine pancreas. Coll Am Pathol. 2016;6:66.

23. Chatterjee D, Katz MH, Rashid A, et al. Histologic grading of the extent of residual carcinoma following neoadjuvant chemoradiation in pancreatic ductal adenocarcinoma: a predictor for patient outcome. Cancer. 2012;118(12):3182-90. https://doi.org/10.1002/cncr.26651.

24. Palorini F, Rancati T, Cozzarini C, et al. Multi-variable models of large International Prostate Symptom Score worsening at the end of therapy in prostate cancer radiotherapy. Radiother Oncol. 2016;118(1):92-8. https://doi.org/10.1016/j.radonc.2015.11.036.

25. van Roessel S, Janssen BV, Soer EC, et al. Scoring of tumour response after neoadjuvant therapy in resected pancreatic cancer: systematic review. Br J Surg. 2021;108(2):119-27. https://doi. org/10.1093/bjs/znaa031.

26. Lee SM, Katz MHG, Liu L, et al. Validation of a proposed tumor regression grading scheme for pancreatic ductal adenocarcinoma after neoadjuvant therapy as a prognostic indicator for survival. Am J Surg Pathol. 2016;40(12):1653-60. https://doi.org/10.1097/ PAS.0000000000000738.

27. Kim SS, Ko AH, Nakakura EK, et al. Comparison of tumor regression grading of residual pancreatic ductal adenocarcinoma following neoadjuvant chemotherapy without radiation. Am J Surg Pathol. 2019;43(3):334-40. https://doi.org/10.1097/PAS. 0000000000001152.

28. Matsuda Y, Ohkubo S, Nakano-Narusawa Y, et al. Objective assessment of tumor regression in post-neoadjuvant therapy resections for pancreatic ductal adenocarcinoma: comparison of multiple tumor regression grading systems. Sci Rep. 2020;10(1):18278. https://doi.org/10.1038/s41598-020-74067-z.

29. Mandard A-M, Dalibard F, Mandard J-C, et al. Pathologic assessment of tumor regression after preoperative chemoradiotherapy of esophageal carcinoma Clinicopathologic correlations. Cancer. 1994;73(11):2680-6. https://doi.org/10.1002/1097-0142(19940601 )73:11\%3c2680::AID-CNCR2820731105\%3e3.0.CO;2-C.

30. Thies S, Langer R. Tumor regression grading of gastrointestinal carcinomas after neoadjuvant treatment. Front Oncol. 2013;3:1-7. https://doi.org/10.3389/fonc.2013.00262.

31. Haeberle L, Insilla AC, Kapp A-C, et al. Stroma composition and proliferative activity are related to therapy response in neoadjuvant treated pancreatic ductal adenocarcinoma. Histol Histopathol. 2020. https://doi.org/10.14670/HH-18-332.

32. Wang H, Chatterjee D, Katz MH, et al. Perineural and intraneural invasion in posttherapy pancreaticoduodenectomy specimens predicts poor prognosis in patients with pancreatic ductal adenocarcinoma. Am J Surg Pathol. 2012;36(3):409-17. https://doi. org/10.1097/PAS.0b013e31824104c5.

33. Elshaer M, Gravante G, Kosmin M, Riaz A, Al-Bahrani A. A systematic review of the prognostic value of lymph node ratio, number of positive nodes and total nodes examined in pancreatic ductal adenocarcinoma. Ann $R$ Coll Surg Engl. 2017;99(2):101-6. https://doi.org/10.1308/rcsann.2016.0340.

Publisher's Note Springer Nature remains neutral with regard to jurisdictional claims in published maps and institutional affiliations. 